\title{
Carbon Emission Reduction Path of China: Industrial Policy and Low-Carbon Education
}

\author{
Shan OUYANG \\ Law School, \\ Yunnan University of Finance and Economics, \\ Kunming, Yunnan, China
}

\author{
Peng NAI* \\ Law School, \\ Yunnan University of Finance and Economics, \\ Kunming, Yunnan, China \\ npeng315@foxmail.com \\ *Corresponding author
}

\begin{abstract}
Carbon emission reduction means reduction of greenhouse gases represented by $\mathrm{CO}_{2}$. Currently China promotes carbon emission reduction by the path of formulating and implementing industrial policies related to carbon emission reduction. Will industrial policy as a carbon emission reduction path be enough to achieve China's carbon emission reduction task? China does not announce official data of carbon-emission quantity from industries, but fossil-fuel consumption data from industries were published by the National Bureau of Statistics. Through multiplying the fossil fuel consumption amount by its carbon emission coefficient, each industry's $\mathrm{CO}_{2}$-emission quantity was estimated. Based on estimation, the industrial policy path is enough for fulfilling China's determined contributions which made by Chinese government in Paris Agreement in 2015. That is, to reduce the $\mathrm{CO}_{2}$ emission per unit of GDP by $60 \%-65 \%$ in 2030 compared with 2005 . However, the in-depth environmental ethics nature of carbon emission reduction determines that it is insufficient to continuously reduce the emission of greenhouse gas by industrial policy path only. Developing low-carbon education from environmental ethic level will provide more potential for carbon emission reduction for China after 2030.
\end{abstract}

Keywords-China, Greenhouse Gas, Carbon Emission Reduction, Industrial Policy, Low-carbon Education

\section{INTRODUCTION}

Scientific researches indicate that: in the past one hundred years global climate has undergone a change featured climate warming. The primary reason for the climate change is human activities, especially greenhouse gases represented by $\mathrm{CO}_{2}$ massively discharged from economic activities since the industrial revolution.

Basing on the United Nations Framework Convention on Climate Change passed in May 1992, countries all over the world started cooperation to reduce the emission of greenhouse gases represented by $\mathrm{CO}_{2}$. Up until the 24th Conference of the Parties (COP-24) of United Nations Climate Change Conference held in December 2018, most countries finally passed the rules for implementing Paris Agreement through tough negotiations. For the past 26 years international community has carried out complicated gaming on environment, politics and economy by centering around how to deal with climate change. Meanwhile, China became the second largest economic entity in 2014. Moreover, China submitted her determined contribution goal in reducing greenhouse gas emission on the 21st Conference of the Parties (COP-21) of United Nations Climate Change Conference in 2015.

\section{ANALYSIS ON THE NATURE OF CARBON REDUCTION EMISSION}

Carbon emission reduction means reduction of greenhouse gases represented by $\mathrm{CO}_{2}$. The issue of carbon emission reduction features four-dimensional natures, including environmental ethics, climate science, politics and economics. Among them, environmental ethics is the more profound nature of carbon emission reduction. Evaluation reports issued by Intergovernmental Panel on Climate Change continuously point out that greenhouse gas emission has led to climate changes featured global warming up. However, there exists certain controversial in science field regarding the topic that greenhouse gas emission is the cause for climate changes. So far there is not an unified conclusion regarding this issue all over the world. Hence, the science nature is not an in-depth nature of carbon emission reduction.

Under this circumstance, various countries are still willing to invest a lot of resources to deal with climate changes and reduce the emission of greenhouse gases for three reasons. First, science fails to exclude the possibility of serious disasters caused by climate changes and such possibility has urged all countries to take joint actions to prevent it from happening. Second, developing countries are capable of getting support from developed countries for carbon emission reduction in environmental technology and fund. So participating in carbon emission reduction is conducive to most developing countries. Third, different proposals from European Union, the United States and China regarding climate change and carbon emission reduction are affecting the international landscape of climate change. Objectively, carbon emission reduction becomes a platform to show political influence of different countries. Among them, the first reason is the fundamental and non-replaceable reason that has got all countries together. It shows the environmental ethics nature of climate change and carbon emission reduction.

The issue of greenhouse gas emission reduction represented by $\mathrm{CO}_{2}$ goes beyond a scientific issue, political 
issue or economic issue. Carbon emission reduction is also an issue of environmental ethics in order to protect the common environmental interests to human beings. which should not to be overlooked in a deeper level. The deepest nature of carbon emission reduction is environmental ethics nature. All activities centering around carbon emission reduction show that human beings are willing to admit the impact from environment for human existence, that human beings are reevaluating their relationship with environment and that human beings are willing to to deal with environmental crises and improve the relationship. The environmental ethics nature of carbon emission reduction has given rise to other international political and economic issues on carbon emission reduction. The in-depth environmental ethics nature determined that it is inadequate to effectively reduce $\mathrm{CO}_{2}$ emission only through industrial policy path.

\section{The Whole Situation OF ChinA’s CARBOn EMission}

China, as a big country in manufacturing, has discharged $\mathrm{CO}_{2}$ through economic activities that has greatly affected global climate change. According to the data announced by National Bureau of Statistics of China [1] and the author's calculation about carbon emission of China from 2005 to 2015 , the whole $\mathrm{CO}_{2}$ emission situation of China's three main industries(industry, agriculture and services) is:

The duration from 2005 to 2013 was a period where the total carbon emission from China's three main industries increased continuously from 6.47 billion tons to 11.28 billion tons. The average increase is about $7.6 \%$. During the period, the increase in 2009 was as highest as $13.9 \%$.

2010 was a turning point where the annual increase level of total carbon emission of the three industries began to decline. From 2010 to 2013, though the total carbon emission of the three industries kept increasing year by year, the increase level has declined significantly.

In 2014 the total carbon emission of the three industries began to show negative increase for the first time and the total carbon emission was 11.51 billion tons. Compared with 2013, the increase level was $-0.8 \%$. In 2015, the total carbon emission of the three industries was 11.28 billion tons; compared with 2014, the increase level was $-2.0 \%$. In 2015, the total carbon emission of the three industries increased by 74.5\% compared with that in 2005.

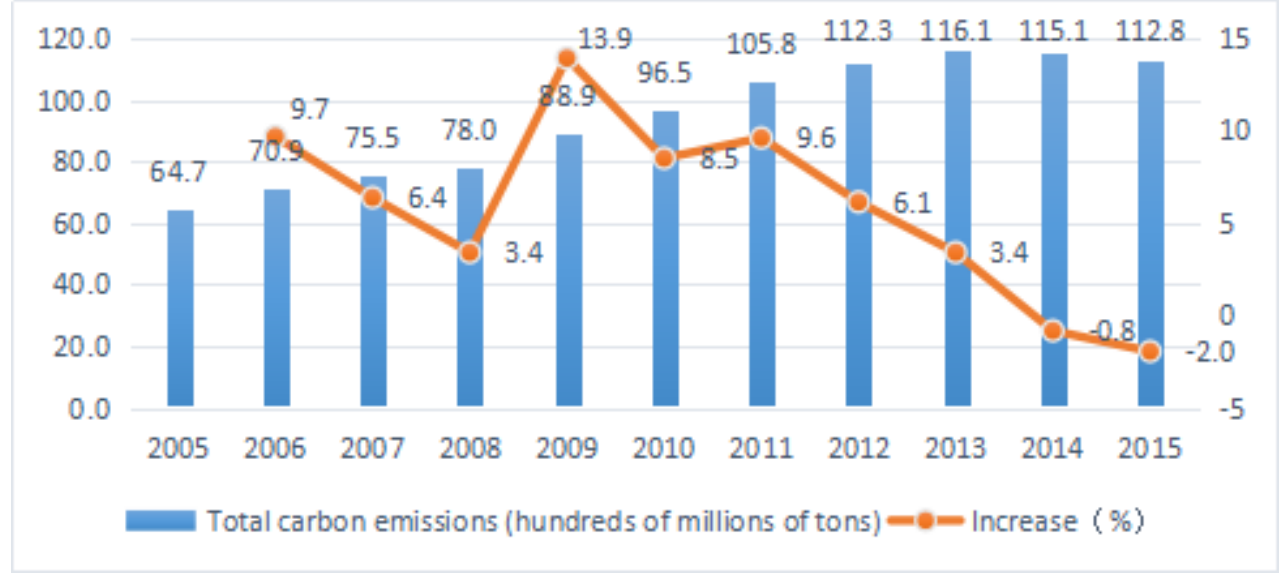

Fig. 1. Calculated Carbon Emissions of China from 2005-2015.

\section{CHINA's CENTRAL GOVERNMENT's STRATEGIC IDEAS AND SPECIFIC GOALS ON CLIMATE CHANGE}

Undoubtedly, China attaches great importance to climate change and regards the issue as a national strategy. China must strive to seize the opportunity and the highest point of low-carbon development, to optimize the resource structure by reducing greenhouse gas emissions. Promoting low-carbon economy has become an unshakable national trends.[2] Based on the speeches of Chinese leaders on global climate change conference and policy documents related to China's climate change, China's central government's strategic ideas on climate change include:

Admit the huge challenge to China's economy and environment caused by climate change.

View climate change as an opportunity for economic transformation which transform the high-emission and low-energy utilization economy to green economy featured low-carbon emission.

Take climate change as a stage for international relations and make use of that to establish a responsible and productive image of China.

The latest goal of China's carbon emission reduction is "the Intended Nationally Determined Contributions" proposed by Chinese president Xi Jinping on the Paris Climate Change Conference: China will make the $\mathrm{CO}_{2}$ emission reach its peak in about 2030 and achieve that as soon as possible; in 2030 the $\mathrm{CO}_{2}$ emission per unit of GDP will decrease by $60 \%$ to $65 \%$ compared with 2005; the non-fossil energy will account for about $20 \%$ of primary energy consumption and the forest growing stock will increase by about 4.5 billion cubic meters. On the $23^{\text {rd }}$ United Nations Climate Change Conference that held on November 18 of 2017 in Bonn Germany, China specified its clear attitude of continuing implementing the 
intended nationally determined contributions of Paris Agreement.

\section{INDUSTRIAL POLICIES APPLIED FOR CHINA's GOAL OF CARBON EMISSION REDUCTION}

Chinese government has applied industrial policies as the primary means to drive $\mathrm{CO}_{2}$ emission reduction. Central government and local government have issued a lot of industry policies, administratively. Administrative policies have some advantages than legislation regarding $\mathrm{CO}_{2}$ emission reduction: administrative policies are very flexible and easy to adjust, so they can adapt to changes to the obligation of carbon emission reduction; administrative policies are very specific, so they can better intervene in carbon emissions in different industries; administrative policies have high executive force and can greatly drive carbon emission reduction through governments and government departments.

Industry policies issued by State Council of China are called "administrative regulations" which have the highest degree of validity among all policies and validity all over the country. Up until March 11 of 2018, there are 8 administrative regulations in total when searching with key words as climate change and greenhouse gas. Among them the representative administrative regulations are Notice for Controlling Greenhouse Gas Emission Work Program during the 13th Five-Year Plan by State Council (2016) and Report of State Council on Climate Change Work (2009).

Industry policies issued by internal departments in state council of China are called "department regulations". Among all policies, department regulations are inferior only to administrative regulations in validity and have validity within the range of the department. Up until March 11 of 2018, there are 75 department regulations in total when searching with key words as climate change and greenhouse gas. Among them, representative department regulations are: Interim Measures for the Management of Greenhouse Gas Voluntary Emission Reduction (2012) and Interim Measures for Carbon Emission Trade Management (2015).

Analyzing above administrative and department regulations, China's policies related to carbon emission reduction primarily cover six areas: forestry, industry, agriculture, traffic, architecture, science and technology, and meteorological department. In the earliest time China handled climate change by increasing carbon sink through afforestation from 2007. Such practice has little impact on domestic economy and is easy to carry out. The time of restricting $\mathrm{CO}_{2}$ emission in industrial area started later from 2012, considering the necessity for keeping economic growth stably.

\section{The METhods FOR ChinA’s INDUSTRIAL POLICIES TO BE EFFECTIVE}

There are two methods: the first one is relying on administrative power and the second one is relying on market transaction of carbon emission amount. Currently the two methods mutually support. The first method plays a leading role and the market transaction plays an assisting role. China's effective experiences on driving carbon emission reduction with administrative power is:

\section{A. Leader groups in governments and departments}

Establish leader groups on different levels to guarantee the administrative force in dealing with climate change. Chinese government has established leader groups both on central government level and on local government level. Meanwhile, many departments including forestry, agriculture and traffic departments also have established corresponding leader groups. These leader groups have constituted a system that facilitates the communication and implementation of any administrative policy or action related to climate change.

\section{B. Assessment on the responsibility of reducing greenhouse gas emission target}

The central government evaluates every provincial government's greenhouse gas emission control task and announce the result all over the country to effectively drive all provincial governments to complete the task. It was named "Control Greenhouse Gas Emission Goal Responsibility Assessment". According to Notice of 2016 Provincial Governments Control Greenhouse Gas Emission Goal Responsibility Assessment and Comment Result announced by the National Development and Reform Commission of the People's Republic of China, only four administrative regions of Chinese 31 provinces, municipalities and autonomous regions failed in the assessment and all the other regions were excellent or good in the assessment.

\section{Carbon emission quota transaction system experiment}

As the second method, carbon emission quota transaction system experiment was conducted in 1 province and 6 cities of China. The seven experimental areas are: Beijing, Shanghai, Chongqing, Guangzhou, Tianjin, Shenzhen and Hubei province. Local governments of the seven provinces and cities have established a specific carbon emission amount transaction system. Enterprises with high carbon emission in the seven provinces has been required to participate in the system and conduct carbon emission quota transaction. The carbon emission quota offered by local governments to enterprises decreases year by year, so more pressure on greenhouse gas emission reduction will be imposed on the enterprises. Consequently, a reversed mechanism has been formed on the enterprises, urging them to reduce $\mathrm{CO}_{2}$ emission through improving energy efficiency and techniques. Finally, the transformation to low-carbon type will be achieved for Chinese enterprises, especially for the manufacturing industry.

\section{ESTIMATION ON CARBON EMISSION REDUCTION EFFECT OF INDUSTRIAL POLICY PATH}

In 2016 Chinese president $\mathrm{Xi}$ Jinping promised on the Paris Climate Change Conference that "In 2030, the $\mathrm{CO}_{2}$ emission per unit of GDP will reduce by $60 \%$ to $65 \%$ compared with 2005”. Based on data estimation, China has a high probability to fulfill this international promise.

Under the industrial policies, the carbon emission per unit of GDP in China is shown as figure below. From 2005 to 2015 the carbon emission amount per unit of GDP decreased continuously (except for the slight increase in 2009). In 2015 
the carbon emission amount per unit of GDP decreased by $52.6 \%$ compared with 2005, the average annual decrease was 1,650 tons/hundred million CNY and the average annual increase was $-7.1 \%$. The data indicate that: if China wants to decrease its carbon emission by $60 \%$ to $65 \%$ in 2030 compared with 2005, it will have to control the carbon emission amount per unit of GDP within 12,085 to 13,811 tons. China will need to decrease the carbon emission per unit of GDP by 2,566 to 4,292 tons/hundred million CNY compared with the level in 2015. As long as China decreases the annual emission by 1,650 tons/ hundred million CNY on average. It is expectative that China will fulfill her international promise in 2030.

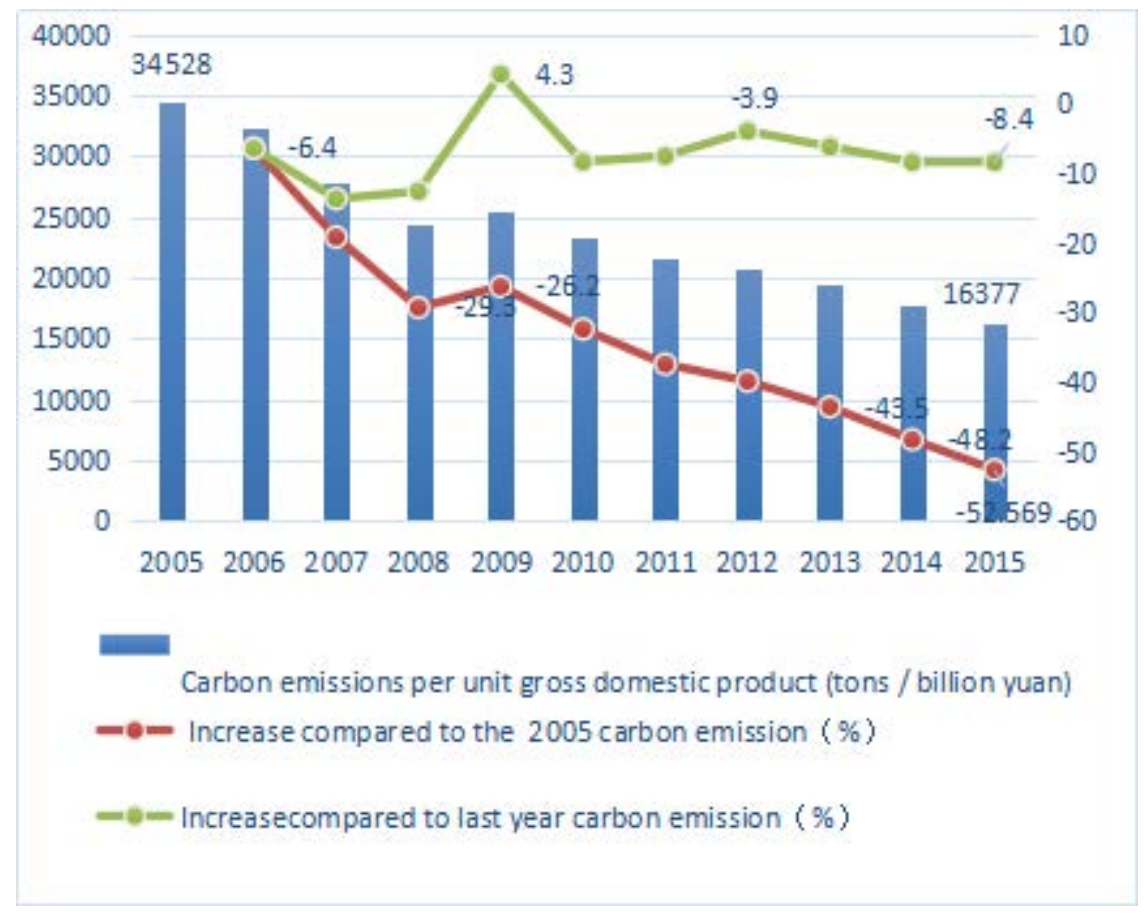

Fig. 2. Calculate Increase of Carbon Emission per Unit of GDP in China from 2005-2015.

\section{LOW-CARBON EDUCATION: A DEVELOPING PATH OF CHINA AFTER 2030 FOR CARBON EMISSION REDUCTION}

It is prospectively that China will fulfill its promise to reduce carbon emission in the latest issue of Paris Agreement by relying on its carbon emission reduction industrial policy. However, it is necessary to consider how to continuously lower greenhouse gas emission after 2030. So far China's low-carbon education remains at the initial stage with great potential for development.

Though Chinese enterprises are actually feeling environmental pressure or chances from carbon emission reduction, such concern is more on benefit or loss from economic perspective. Chinese enterprises are lacking of concern on the environmental impact from their economic operation from perspective of environmental ethics as well as their responsibilities for that. Moreover, low-carbon education is still not popularized in China's higher education institutes. When buying take-away food and other commodities and services, Chinese college students tend to consider the convenience and price instead of the carbon cost. Academic studies on carbon emission reduction generally focusing on low carbon economy, carbon tax, carbon trade, carbon neutral, carbon supply chain according to the result of searching on CNKI system. [3] To sum up, low-carbon education is not a hot research topic in China's carbon emission reduction. There are relatively few research achievements on lowering $\mathrm{CO}_{2}$ emission from perspective of environmental ethics. Compared to Japan, environment protection has been set as required courses in education system. Learners of different ages will receive different environmental courses.[4] Harvard University, Yale University, Brown University, Tokyo University and many world-famous universities have begun to build low-carbon campuses. These universities have made a detailed analysis and plan of $\mathrm{CO}_{2}$ emission sources, current emissions, quantifying methods, and specific measures to reduce $\mathrm{CO}_{2}$ emissions in the campus.[5]

The philosophical foundation of low-carbon education is the relation between human being and the nature. [6] China should establish the environmental ethics concept on climate change among students, enterprises and the whole society so as to convert the economic responsibility of carbon emission reduction into moral obligation of human beings and create long-term and stable motive for carbon emission reduction. To create more potential for carbon emission reduction in China after 2030, developing low-carbon education from environmental ethics perspective is a path worth considering.

\section{CONCLUSION}

Although the industrial policy emission reduction path can meet China's carbon emission reduction needs before 2030, 
but China should consider developing low-carbon education as a way to provide a longer-term incentive to cut $\mathrm{CO}_{2}$ emissions.

\section{REFERENCES}

[1] Statics was fetched from National Bureau of Statistics of China and was reorganized by author. [EB/OL].[2018-01-13].http://www.stats.gov.cn (In Chinese).

[2] Tong Xin, Li Xueseng. A Review of Frontier Literature on Regional Carbon Emission and Reduction Path[J].Inquiry into Economic Issues,2017(1):169-176 (In Chinese).
[3] Yang Wei, Cheng Xiaoting. Research Hotspot of China's Carbon Emission Reduction and Its Knowledge Map of Evolution[J].Journal of Changsha University,2019,33(3):19-24 (In Chinese).

[4] Qiu Ji. Japan's Low Carbon Value Promotion Model and Enlightenment[J].Urban Management Science \& Technology,2014(3):28-30 (In Chinese).

[5] Wei Hongmei. Analysis about the Content and Way of Low-carbon Education in Vocational Colleges under the Background of Low-carbon Economy[J].Journal of Qiqihar Junior Teachers' College,2015(3):45-47 (In Chinese).

[6] Liang Yanliang, Zhang Xing. On the Three Ethical Dimensions of the Low-Carbon Lifestyle Education[J].Tribune of Education Culture,2018(4):26-29 (In Chinese). 